\title{
Knowledge and Practice of Hearing Screening and Hearing Loss Management among Ear, Nose, and Throat Physicians in Jordan
}

\author{
Maha Zaitoun ${ }^{1}$ Mohammad Rawashdeh ${ }^{1}{ }^{\circledR}$ Safa AlQudah ${ }^{10}$ Hana' ALMohammad ${ }^{10}$ \\ Amjad Nuseir ${ }^{10}$ Feda Al-tamimi ${ }^{10}$
}

${ }^{1}$ Department of Rehabilitation Sciences, Jordan University of Science and Technology, Irbid, Jordan

Int Arch Otorhinolaryngol 2021;25(1):e98-e107.

\author{
Address for correspondence Maha Zaitoun, PhD, Assistant Professor \\ of Audiology, Department of Rehabilitation Sciences, Faculty of \\ Applied Medical Sciences, Jordan University of Science and \\ Technology, Jordan/Irbid 22110, Jordan \\ (e-mail: mmzaitoun@just.edu.jo).
}

\begin{abstract}
Keywords

- health knowledge

- attitudes

- practice

- otolaryngology

- hearing

Introduction One of the main factors that affect the early diagnosis and intervention of hearing loss is inadequate knowledge by the health care workers. Ear, nose, and throat (ENT) specialists are the main source of information about hearing loss and its management in most developing countries, such as Jordan.

Objective The purpose of the present study is to explore the level of knowledge and the practice of hearing screening and hearing loss management for children among ENT physicians in Jordan as an example of health care providers in developing countries of the Middle East.

Methods This was a cross-sectional study, adapting a questionnaire of knowledge and the practice of hearing screening and hearing loss management for children. The questionnaire consisted of 2 sections with 20 questions. A total of 40 ENT physicians completed the questionnaire.

Results The majority of the respondents acknowledged the importance of hearing screening for children; however, there was limited knowledge regarding hearing loss management and testing. Only 10 of the ENT physicians believed that a referral to an audiologist is warranted, and the majority of the respondents were not aware that a child with a confirmed permanent hearing loss should be referred to a speech pathologist or to a rehabilitation center. Managing unilateral and mild sensorineural hearing loss (SNHL) was another area about which ENT physicians have limited knowledge.

Conclusion There is a strong need for professional intervention programs, providing the latest updates and standardizations in the field of audiology and pediatric rehabilitation for ENT physicians.
\end{abstract}

\section{Introduction}

Hearing loss is one of the most common disorders found at birth. Population-based studies have found prevalence rates ranging from 1 to 5 per 1,000 live births. ${ }^{1,2}$ Hearing loss can adversely affect the receptive and expressive communication skills of the child; his/her educational achievements will be affected accordingly. ${ }^{3-5}$ In Jordan, as in all other developing countries, where the received

November 10, 2019

accepted

January 25, 2020

published online

April 29, 2020
DOI https://doi.org/ 10.1055/s-0040-1709112. ISSN 1809-9777.

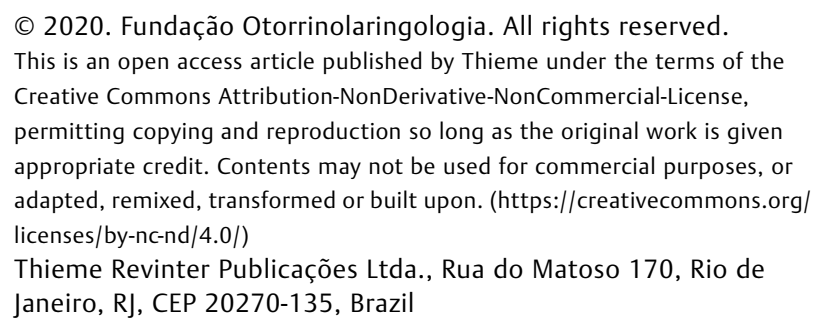


majority of children with hearing loss live, ${ }^{6}$ the outlook is bleaker due to higher levels of poverty that reduce access to early identification of hearing loss and early intervention., ${ }^{6,7}$ Implementing a newborn hearing screening program (NHSP) to detect hearing loss early in life can dramatically reduce the impact of hearing loss. ${ }^{8}$ Unfortunately, such programs are not well-established or do not even exist in some developing countries. ${ }^{9}$

One of the main factors that affect early diagnosis and intervention in hearing loss is inadequate knowledge among medical health workers. ${ }^{10}$ The concern is even greater in developing countries like Jordan, where NHSP is not wellestablished. Several medical practitioners are involved in testing newborns and children for hearing, such as pediatricians, obstetricians/gynecologists, audiologists and ear, nose and throat (ENT) specialists. ${ }^{10-12}$

In Jordan, as well as in most Middle East countries, otolaryngologists are the first and main source of information about hearing loss, its impact and management. The audiologists would usually conduct hearing rehabilitation and the decision to go for specific management is strongly supported and affected by the ENT specialists.

Several studies have examined the knowledge, attitude and practice of newborn hearing screening (NHS) among medical professionals across the world for various areas of medical specializations, ${ }^{13}$ such as physicians, ${ }^{11,14}$ pediatricians, ${ }^{15-18}$ midwives ${ }^{19}$ and mixed samples of physicians and pediatricians. ${ }^{20,21}$ Previous reports have shown a poor to fair level of knowledge about NHS relating to information, 12,19,22 positive attitude ${ }^{3,11,18,23}$ and effective procedures. ${ }^{15,19,23}$ However, none of these studies has been conducted in Jordan or any developing country. Therefore, the present study investigated the knowledge and practices associated with hearing loss, its impact and management among ENT specialists in Jordan, as an example of health care practitioners in developing countries of the Middle East.

\section{Methods}

Based on quantitative methodology, a cross-sectional study was conducted during the $9^{\text {th }}$ International Congress of the Jordanian Society of Otorhinolaryngology Head \& Neck Surgery that was held in Amman, Jordan, May 2018. The questionnaires were distributed to the attendees at the beginning of the sessions, and were collected after the sessions. A paragraph describing the aim of the study was included at the beginning of the survey. Anonymity was ensured, as no personal questions were included. Approval for the present study was obtained from the ethics committee at the Jordan University of Science and Technology (number 299-2018). A total of 42 copies of the questionnaire were returned. Of these, two were almost blank; therefore, they were excluded from the analysis. (-Supplementary Appendix A [Available online]).

\section{Population and Sample}

The population in the present study consisted of all the working ENT physicians in Jordan. In Jordan, ENT physicians work in four main sectors: Ministry of Health, Royal Military Medical Services, university teaching hospitals, and in the private sector. The otolaryngologists must complete 5 years of residency training program in an accredited hospital. The $1^{\text {st }}$ year of residency is usually allocated in the general surgery department. All otolaryngologists should pass a two-step exam, the first one concentrates on basic sciences and the second concentrates on clinical sciences. There is $\sim 150$ working otolaryngologists registered in the health system. The sample of the study was gathered during an annual conference for the ENT physicians in Jordan where the majority of them attend every year. The 40 otolaryngologists who completed the study questionnaire were estimated to give an $80 \%$ chance of detecting correlations of \pm .223 at $p \leq 0.05$ using Cohen equation (1992) for power sample, thus representing the population of the study.

\section{The Questionnaire}

The questionnaire was adapted from Moeller et $\mathrm{al}^{21}$ with modifications contextually relevant to the current study. It was used to investigate the level of knowledge and the practice of hearing loss management among ENT professionals in Jordan. The modifications included new questions related directly to hearing screening and management of hearing loss in Jordan. Two new questions were related to the knowledge of the best hearing screening test and the suitable audiological management of pediatric patients. The questionnaire consisted of 20 questions divided over 2 sections. The first section consisted of seven questions related to the demographic background of the respondents, such as specialty, years of experience, age, gender and practice setting. The respondents were also asked about the number of newborns for whom they received NHS results and the estimated number of permanent sensorineural hearing loss (SNHL) children they examined over the past 3 years. The second section consisted of 13 questions related to the level of knowledge and practice with regard to hearing loss and its management. All of the questions were in English; they varied between yes/no, multiple choice and short written answers.

\section{Validation of the Study Tool}

To validate the modified questionnaire, a panel of researchers consisting of an ENT specialist at the King Abdullah II University Hospital (KAUH) with 5 years of experience and 3 assistant professors in audiology from the Department of Applied Medical Sciences at the Jordan University of Sciences and Technology (JUST) reviewed it. Feedback from the research panel was taken into consideration and all necessary modifications were made. The questionnaire was then distributed to 10 ENT residents for feedback to guarantee that all questions were clear. The internal consistency of the questionnaire was determined (Cronbach $\alpha=0.77-0.85$ ), reflecting good validity; therefore no further changes were made. The reliability of the questionnaire was assessed by resubmitting the questionnaire to the same 10 ENT residents and comparing their responses. The test-retest reliability of the questionnaire was good (kappa score $=0.61-0.71$ ). The responses of the 10 ENT residents were not included in the sample for the present study.

\section{Data Analysis}

All data gathered by the questionnaire were coded into variables and were analyzed using the (BM SPSS Statistics 
for Windows, Version 20.0. Armonk, NY: IBM Corp.) software program. Descriptive analysis was conducted for each question to determine sample characteristics. For some questions, comparisons were made between the ENT physicians using a chi-squared test. For each test, a $p$-value $<0.05$ was considered statistically significant. For the short answer questions, a qualitative method of analysis was followed by organizing the answers into groups of similar responses, and then determining the frequencies for each group.

\section{Results}

\section{Demographic Information}

The demographic information of the participants is presented in - Table 1. A total of 40 ENT physicians participated in the present study, with 18 (45\%) being specialists and 22 (55\%) residents. Almost half of the participants had $<5$ years of experience in practice, while $4(10 \%)$ had $>15$ years of experience. Regarding variation in age, $50 \%$ of the study sample were $<30$ years old. The majority of the ENT physicians (80.0\%) were males, and 21 (52.5\%) worked in a university hospital. Of the 40 respondents, 15 (35.7\%) did not receive any NHS results in their practice. A total of 27 (67.5\%) of the participants had children with permanent SNHL in their practice over the past 3 years ( - Table 1 ).

\section{Questions Regarding Knowledge Related to Hearing Screening Programs}

A majority of the respondents (85\%) indicated that screening all newborns for permanent hearing loss was very important, while 5 respondents $(12.5 \%$ ) considered it somewhat important. More than half of the participants (24 out of 40) believed that hearing screening programs caused excessive parent anxiety.

When asking about which component of audiology physicians were interested in gaining more information about, answers were highest for auditory brain-stem response (ABR) or acoustic reflexes testing (16.7\%), followed by cochlear implants (9.5\%).

\section{Knowledge of Risk Factors}

-Table 2 summarizes the answers from the participants regarding factors that put a child at risk of late-onset hearing loss. The question contained 10 answer options, with only 6

Table 1 Demographic information of the respondents

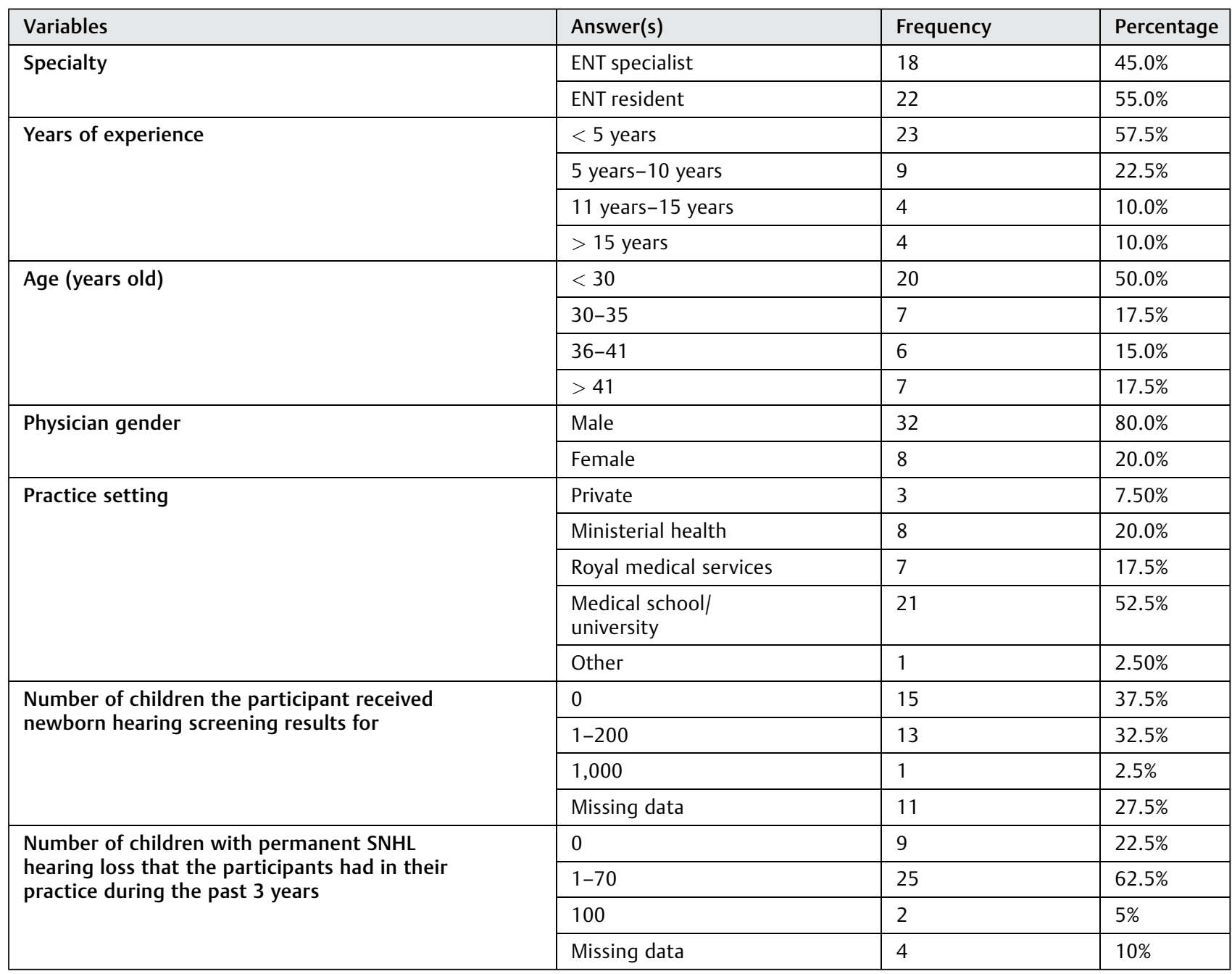


Table 2 Responses of the physicians regarding factors that put a child at risk for permanent late onset hearing loss

\begin{tabular}{|l|l|l|l|}
\hline Risk factors & Overall & Specialist & Resident \\
\hline Meningitis* & $34(85 \%)$ & $16(47.1 \%)$ & $18(52.9 \%)$ \\
\hline Congenital syphilis* & $4(10 \%)$ & $4(100 \%)$ & $0(0 \%)$ \\
\hline Frequent colds & $17(42.5 \%)$ & $9(52.9 \%)$ & $8(47.1 \%)$ \\
\hline Hypotonia & $5(12.5 \%)$ & $2(40 \%)$ & $3(60 \%)$ \\
\hline$\geq 48$ hours in NICU* & $6(15 \%)$ & $2(33.3 \%)$ & $4(66.7 \%)$ \\
\hline $\begin{array}{l}\text { Family history } \\
\text { of hearing loss* }\end{array}$ & $27(67.5 \%)$ & $14(51.8 \%)$ & $13(48.2 \%)$ \\
\hline Cleft palate* & $7(17.5 \%)$ & $3(42.8 \%)$ & $4(57.2 \%)$ \\
\hline $\begin{array}{l}\text { Cytomegalovirus } \\
\text { (CMV) }\end{array}$ & $35(87.5 \%)$ & $17(48.6 \%)$ & $18(51.4 \%)$ \\
\hline $\begin{array}{l}\text { Mother }>40 \text { years } \\
\text { old }\end{array}$ & $28(70 \%)$ & $14(50 \%)$ & $14(50 \%)$ \\
\hline $\begin{array}{l}\text { Congenital } \\
\text { heart disease }\end{array}$ & $8(20 \%)$ & $5(62.5 \%)$ & $3(37.5 \%)$ \\
\hline Missing data & $3(7.5 \%)$ & $1(33.3 \%)$ & $2(66.7 \%)$ \\
\hline
\end{tabular}

*indicates the right answer.

of these being risk factors, which were identified by a star $\left({ }^{*}\right)$ symbol in -Table 2. For this question, a comparison was made between ENT specialists and residents.

Both cytomegalovirus (CMV) and meningitis were the most frequent factors to be identified by 35 (87.5\%) and 34 (85\%) of the 40 respondents, respectively. Mothers aged $>40$ years old at childbirth was misidentified as a risk factor by $70 \%$ of the respondents, and a family history of hearing loss was erroneously selected by $67.5 \%$. Only 4 out of the 40 respondents correctly identified congenital syphilis as a risk factor, and all of these were specialists. Similarly, only 6 out of the 40 participants were able to identify that staying in a neonatal intensive care unit (NICU) for $>48$ hours puts a child at risk of late-onset hearing loss, of whom 4 were residents and only 2 were specialists. Only seven participants identified cleft palate as a risk factor, of whom four where residents and three were specialists.

Out of the 40 respondents, only 2 (5\%) identified correctly all 6 risk factors. On the other hand, only 4 participants (10\%) identified just 1 out of the 6 factors, and only 2 (5\%) were not able to correctly identify any of the risk factors. A significant difference between specialists and residents was only found for one risk factor, congenital syphilis, in favor of the specialists, with no resident identifying it as a risk factor.

\section{Ages of Follow-up Procedures}

- Table 3 lists the estimates given by the respondents of ages at which follow-up procedures should be conducted in children. The first part of the question investigated knowledge regarding the right age for additional testing in the case of a newborn who did not pass the hearing screening. Only 15 out of 40 ENT physicians (37.5\%) correctly identified the answer as $<1$ month. Of the 15 respondents who knew the right age, 7 (46.6\%) were specialists, and 11 (73.3\%) worked in a medical school/university setting. The second part of the question concerned the age when a child could definitely be diagnosed as having permanent hearing loss. A total of 14 out 40 physicians (35\%) correctly identified it to be at less than between 1 and 3 months. Of these 14 respondents, 8 (57.1\%) were specialists and 6 (42.8\%) were residents. Eight of the 14 physicians $(57.1 \%)$ worked in a medical school/university setting.

When the respondents were asked to define the age when a child can begin wearing a hearing aid, 12 (30\%) out of 40 indicated less than between 1 and 3 months. Four (33.3\%) of these 12 physicians were specialists and 8 were residents; in addition, 9 (75\%) of them worked in a medical school/university setting.

A total of 14 (35\%) of the 40 respondents correctly answered that early intervention services should be instigated at less than between 1 and 6 months of age for a child with permanent hearing loss. Of these 14 respondents, 6

Table 3 Estimates of the physicians of the right ages for conducting the follow-up procedures

\begin{tabular}{|l|l|l|l|l|l|l|l|}
\hline & Sample & $\begin{array}{l}\leq 1 \\
\text { month }\end{array}$ & $\begin{array}{l}1-3 \\
\text { months }\end{array}$ & $\begin{array}{l}3-6 \\
\text { months }\end{array}$ & $\begin{array}{l}\text { 6-9 } \\
\text { months }\end{array}$ & $\begin{array}{l}\text { 9-12 } \\
\text { months }\end{array}$ & $\begin{array}{l}\text { Missing } \\
\text { data }\end{array}$ \\
\hline \multirow{2}{*}{$\begin{array}{l}\text { A newborn not passing } \\
\text { the hearing screening } \\
\text { should receive } \\
\text { additional testing }\end{array}$} & Whole sample & $15(35.7 \%)^{*}$ & $16(38.1 \%)$ & $8(19.0 \%)$ & - & - & $1(2.5 \%)$ \\
\cline { 2 - 7 } & Specialist & $7(46.6 \%)$ & $10(62.5 \%)$ & $3(37.5 \%)$ & 0 & 0 & 0 \\
\cline { 2 - 7 } & Resident & $8(53.4 \%)$ & $6(37.5 \%)$ & $5(62.5 \%)$ & 0 & 0 & $1(100 \%)$ \\
\hline $\begin{array}{l}\text { A child can be definitely } \\
\text { diagnosed as having } \\
\text { permanent hearing loss }\end{array}$ & Whole sample & $7(16.7 \%)^{*}$ & $7(16.7 \%)^{*}$ & $18(42.9 \%)$ & $2(4.8 \%)$ & $4(9.5 \%)$ & $2(5 \%)$ \\
\cline { 2 - 7 } & Specialist & $4(57.1 \%)$ & $4(57.1 \%)$ & $10(55.5 \%)$ & 0 & 0 & 0 \\
\cline { 2 - 7 } & Resident & $3(42.9 \%)$ & $3(42.9 \%)$ & $8(44.5 \%)$ & $2(100 \%)$ & $4(100 \%)$ & $2(100 \%)$ \\
\hline \multirow{2}{*}{$\begin{array}{l}\text { A child can begin } \\
\text { wearing hearing aids }\end{array}$} & Whole sample & $5(11.9 \%)^{*}$ & $7(16.7 \%)^{*}$ & $9(21.4 \%)$ & $7(16.7 \%)$ & $10(23.8 \%)$ & $2(5 \%)$ \\
\cline { 2 - 7 } & Specialist & $1(20 \%)$ & $3(42.9 \%)$ & $6(66.7 \%)$ & $3(42.9 \%)$ & $5(50 \%)$ & 0 \\
\cline { 2 - 7 } & Resident & $4(80 \%)$ & $4(57.1 \%)$ & $3(44.3 \%)$ & $4(57.1 \%)$ & $5(50 \%)$ & $2(100 \%)$ \\
\hline \multirow{2}{*}{$\begin{array}{l}\text { A child with permanent } \\
\text { hearing loss be referred } \\
\text { to early intervention } \\
\text { services }\end{array}$} & Whole sample & $6(14.3 \%)^{*}$ & $6(14.3 \%)^{*}$ & $2(4.8 \%)^{*}$ & $11(26.2 \%)$ & $12(28.6 \%)$ & $3(7.5 \%)$ \\
\cline { 2 - 7 } & Specialist & $1(16.6 \%)$ & $4(66.7 \%)$ & $1(50 \%)$ & $6(54.5 \%)$ & $6(50 \%)$ & 0 \\
\cline { 2 - 7 } & Resident & $5(83.4 \%)$ & $2(33.3 \%)$ & $1(50 \%)$ & $5(45.5 \%)$ & $6(50 \%)$ & $3(100 \%)$ \\
\hline
\end{tabular}

*indicates the right answer. 
Table 4 Estimates of the physicians of the right candidates for cochlear implants

\begin{tabular}{|l|l|l|l|}
\hline & $\begin{array}{l}\text { Whole } \\
\text { sample }\end{array}$ & Specialist & Resident \\
\hline $\begin{array}{l}\text { Infants with bilateral } \\
\text { mild-moderate } \\
\text { hearing loss }\end{array}$ & $2(5 \%)$ & $1(50 \%)$ & $1(50 \%)$ \\
\hline $\begin{array}{l}\text { Infants with bilateral } \\
\text { profound hearing loss* }\end{array}$ & $\begin{array}{l}39 \\
(97.5 \%)^{*}\end{array}$ & $\begin{array}{l}18 \\
(46.2 \%)\end{array}$ & $\begin{array}{l}21 \\
(53.8 \%)\end{array}$ \\
\hline $\begin{array}{l}\text { Infants with unilateral } \\
\text { mild-moderate } \\
\text { hearing loss }\end{array}$ & 0 & 0 & 0 \\
\hline $\begin{array}{l}\text { Infants with unilateral } \\
\text { profound hearing loss }\end{array}$ & $14(35 \%)$ & $6(42.8 \%)$ & $8(57.2 \%)$ \\
\hline Unsure & $1(2.5 \%)$ & 0 & $1(100 \%)$ \\
\hline Missing data & $2(5 \%)$ & 0 & $2(100 \%)$ \\
\hline
\end{tabular}

*indicates the right answer.

(42.8\%) were specialists, and 9 (64.3\%) worked in a medical school/university setting. More than half of the participants (57\%) indicated that the right age for intervention was after 6 months, 12 (52.2\%) of whom were specialists. Overall, there was no significant difference between the answers given by specialists and residents for this question.

- Table 4 shows answers given by the respondents regarding the right candidates for cochlear implants among hearing impaired infants. The majority (97.5\%) of the 40 respondents answered it was those infants with profound bilateral hearing loss. No statistical differences were found between the responses of specialists and residents for this question.

- Table 5 shows the answers the respondents gave regarding the best tests for hearing screening programs. Almost half (47.5\%) of the 40 respondents indicated transient evoked otoacoustic emissions (TEOAE) was the best test to be implemented. A total of 12 (30\%) participants gave automated auditory brainstem response (AABR) as the answer, 3 (25\%) of whom were specialists and 9 (75\%) were residents.

Table 5 Estimates of the physicians of the best tests for hearing screening program

\begin{tabular}{|l|l|l|l|}
\hline & $\begin{array}{l}\text { Whole } \\
\text { sample }\end{array}$ & Specialist & Resident \\
\hline $\begin{array}{l}\text { Screening transient } \\
\text { evoked otoacoustic } \\
\text { emission (TEOAE) }\end{array}$ & $\begin{array}{l}19 \\
(47.5 \%)\end{array}$ & $\begin{array}{l}7 \\
(36.8 \%)\end{array}$ & $\begin{array}{l}12 \\
(63.2 \%)\end{array}$ \\
\hline $\begin{array}{l}\text { Screening distortion } \\
\text { product otoacoustic } \\
\text { emission (DPOAE) }\end{array}$ & $6(15 \%)$ & $\begin{array}{l}5 \\
(83.4 \%)\end{array}$ & $\begin{array}{l}1 \\
(16.6 \%)\end{array}$ \\
\hline $\begin{array}{l}\text { Automated auditory } \\
\text { brainstem response } \\
\text { (AABR) }\end{array}$ & $\begin{array}{l}12 \\
(30 \%)^{*}\end{array}$ & $\begin{array}{l}3 \\
(25 \%)\end{array}$ & $\begin{array}{l}9 \\
(75 \%)\end{array}$ \\
\hline $\begin{array}{l}\text { Screening } \\
\text { tympanometry }\end{array}$ & 0 & 0 & 0 \\
\hline Missing data & $2(5 \%)$ & $2(100 \%)$ & 0 \\
\hline
\end{tabular}

*indicates the right answer.
Of these 12 respondents, 6 (50\%) worked in a medical school/university setting. Notably, none of the 40 respondents chose tympanometry screening as the best test to be implemented. No statistical differences were found between the responses of specialists and residents for this question.

\section{Managing Hearing Loss in Children}

- Table 6 summarizes the answers of respondents to five statements regarding the management of hearing loss in children, using one out of five options on a Likert scale. For analysis, the options "strongly agree" and "agree" were considered as a single criterion, "agreeing." Likewise, "strongly disagree" and "disagree" were considered as a single criterion, "disagree." The first statement in the question indicated that children with recurrent conductive issues, such as otitis media, should receive hearing aids along with medication. A majority of physicians $(n=31 ; 77.5 \%)$ disagreed with this statement, and only $5(12.5 \%)$ of the 40 respondents agreed. Of those that agreed with the statement, $4(80 \%)$ were specialists, while $3(60 \%)$ worked in a medical school/university setting.

The second statement indicated that children who received hearing aids or cochlear implants could develop adequate speech and language skills without the need for speech therapy or auditory rehabilitation. A majority of the respondents ( 33 out of $40,82.5 \%$ ) disagreed with this statement, of whom 15 (45.5\%) were specialists and 15 (45.5\%) worked in a medical school/university setting. In contrast, agreement with this statement was only registered by 3 (7.5\%) of the 40 respondents.

The third statement indicated that children with a mild degree of SNHL did not need hearing aids. More than a third of the physicians ( $n=17 ; 42.5 \%)$ agreed with this statement, while 8 (20\%) out of 40 respondents were unsure of their answer. A third (15 out of $40 ; 37.5 \%$ ) of the physicians disagreed with this statement, of which 10 (66.7\%) were specialists, and 6 (40\%) worked in a medical school/university setting.

The fourth statement was "children with unilateral hearing loss may not be fitted with a hearing aid as they have one good (normal) ear." A total of 10 (25\%) of the 40 respondents agreed with this statement, while 7 (17.5\%) were unsure. A total of 23 (57.5\%) of the 40 respondents disagreed with the statement, 12 (52.2\%) of whom were specialists, while 13 (56.5\%) worked in a medical school/university setting.

The fifth statement was "ABR results are preferred over behavioral testing (such as visual reinforcement audiometry [VRA]) to estimate hearing thresholds in children." A majority of the physicians (33 out of $40 ; 82.5 \%$ ) agreed with this statement, of which $14(42.4 \%)$ were specialists. Only 5 (12.5\%) out of 40 physicians disagreed with this statement, of whom $4(80 \%)$ were specialists, and $2(40 \%)$ worked in a medical school/university setting. A total of 2 (5\%) of the 40 respondents were unsure about their answer to this statement.

\section{Questions about Hearing Screening Programs in Jordan}

When asked about hearing screening programs in Jordan, 24 of the 40 respondents (60\%) stated that Jordan had such 
Table 6 Responses of the physicians regarding hearing loss management in children

\begin{tabular}{|c|c|c|c|c|c|c|c|}
\hline Statement & Sample & $\begin{array}{l}\text { Strongly } \\
\text { Agree }\end{array}$ & Agree & Unsure & Disagree & $\begin{array}{l}\text { Strongly } \\
\text { Disagree }\end{array}$ & $\begin{array}{l}\text { Missing } \\
\text { Data }\end{array}$ \\
\hline \multirow{3}{*}{$\begin{array}{l}\text { Children with recurrent } \\
\text { conductive issues such as otitis } \\
\text { media should receive hearing aids } \\
\text { along with medication }\end{array}$} & $\begin{array}{l}\text { Whole } \\
\text { sample }\end{array}$ & $0^{*}$ & $5(12.5 \%)^{*}$ & $4(10 \%)$ & 23(57.5\%) & $8(20 \%)$ & 0 \\
\hline & Specialist & 0 & $4(80 \%)$ & $3(75 \%)$ & $7(30.4 \%)$ & $4(50 \%)$ & 0 \\
\hline & Resident & 0 & $1(20 \%)$ & $1(25 \%)$ & 16 (69.6\%) & $4(50 \%)$ & 0 \\
\hline \multirow{3}{*}{$\begin{array}{l}\text { Children who receive hearing aids } \\
\text { or cochlear implants can develop } \\
\text { adequate speech and language } \\
\text { skills without the need of speech } \\
\text { therapy or auditory rehabilitation }\end{array}$} & $\begin{array}{l}\text { Whole } \\
\text { sample }\end{array}$ & $2(5 \%)$ & $1(2.5 \%)$ & $3(7.5 \%)$ & $19(47.5 \%)^{*}$ & $14(35 \%)^{*}$ & $1(2.5 \%)$ \\
\hline & Specialist & $2(100 \%)$ & 0 & $1(33.3 \%)$ & $8(42.1 \%)$ & 7 (50\%) & 0 \\
\hline & Resident & 0 & $1(100 \%)$ & $2(66.7 \%)$ & 11 (57.9\%) & $7(50 \%)$ & 1 (100\%) \\
\hline \multirow[t]{3}{*}{$\begin{array}{l}\text { Children with mild degree SNHL } \\
\text { do not need hearing aids }\end{array}$} & $\begin{array}{l}\text { Whole } \\
\text { sample }\end{array}$ & $1(2.5 \%)$ & $16(40 \%)$ & $8(20 \%)$ & $12(30 \%)^{*}$ & $3(7.5 \%)^{*}$ & 0 \\
\hline & Specialist & 0 & $6(37.5 \%)$ & $2(25 \%)$ & $8(66.7 \%)$ & 2 (66.7\%) & 0 \\
\hline & Resident & $1(100 \%)$ & 10 (62.5\%) & $6(75 \%)$ & $4(33.3 \%)$ & $1(33.3 \%)$ & 0 \\
\hline \multirow{3}{*}{$\begin{array}{l}\text { Children with unilateral hearing } \\
\text { loss may not be fitted with } \\
\text { hearing aid as they have one good } \\
\text { (normal) ear }\end{array}$} & $\begin{array}{l}\text { Whole } \\
\text { sample }\end{array}$ & 0 & $10(25 \%)$ & 7 (17.5\%) & $19(47.5 \%)^{*}$ & $4(10 \%)^{*}$ & 0 \\
\hline & Specialist & 0 & $5(50 \%)$ & 1 (14.3\%) & $9(47.4 \%)$ & $3(75 \%)$ & 0 \\
\hline & Resident & 0 & $5(50 \%)$ & $6(85.7 \%)$ & 10 (52.6\%) & $1(25 \%)$ & 0 \\
\hline \multirow{3}{*}{$\begin{array}{l}\text { ABR results are preferred over } \\
\text { behavioral testing (such as VRA) } \\
\text { to estimate hearing thresholds in } \\
\text { children }\end{array}$} & $\begin{array}{l}\text { Whole } \\
\text { sample }\end{array}$ & 7 (17.5\%) & $26(65 \%)$ & $2(5 \%)$ & $3(7.5 \%)^{*}$ & $2(5 \%)^{*}$ & 0 \\
\hline & Specialist & $4(57.2 \%)$ & 10 (38.5\%) & 0 & 2 (66.7\%) & $2(100 \%)$ & 0 \\
\hline & Resident & $3(42.8 \%)$ & 16 (61.5\%) & $2(100 \%)$ & $1(33.3 \%)$ & 0 & 0 \\
\hline
\end{tabular}

Abbreviations: ABR, auditory brain-stem response; SNHL, sensorineural hearing loss; VRA, visual reinforcement audiometry.

*indicates the right answer.

programs, while 16 (40\%) were divided evenly between those who did not think there were such programs and those who were unsure. Those answering this question positively were asked to indicate the place and mechanism of a hearing screening program in Jordan. A total of 8 out of the 24 respondents (33.3\%) referred to university hospitals as places for screening, and almost half of them $(45.8 \%)$ indicated that otoacoustic emissions (OAE) testing was the mechanism used for screening. Asked about which places and professional physicians would usually refer a child with a confirmed permanent hearing loss, answers varied between audiologists specializing in cochlear implants $(23.8 \%)$, royal medical services $(23.8 \%)$ and private centers (19\%). Respondents were divided when asked if they faced difficulties in finding places that provide reliable audiology-related services in Jordan. A total of 23 (54.8\%) of the participants claimed that they were aware of different health insurance plans covering audiological services, including hearing screening and cochlear implantation.

\section{Discussion}

Hearing loss has a serious impact on the quality of life of children; hence, it is essential to be detected during infancy for early intervention. Programs of early detection and intervention significantly reduce the effects of hearing loss; however, they are either absent or still at an early stage in developing countries. ${ }^{9}$ The present study was the first of its kind to assess the knowledge and practice of ENT physicians regarding hearing screening and hearing loss management in a developing country, Jordan.

\section{Knowledge of Hearing Screening and Management in General}

The majority of the respondents were aware of the importance of NHS for children. This could be attributed to their knowledge of the negative consequences that hearing loss has on the language and social development of children, ${ }^{19,24}$ and their recognition of the benefits of early detection and intervention programmes. ${ }^{22}$

The present study showed that ENT physicians believed that hearing screening could result in excessive anxiety or concern for parents. This response was consistent with that of other healthcare professionals who felt that NHS cause parental anxiety and affected parent-child bonding. ${ }^{22,25}$ In contrast, several studies refuted this claim, since the behavior of parents could not be accurately measured unless their child underwent a hearing screening. ${ }^{26,27}$

The present study also showed that only 10 out of the 40 ENT physicians (25\%) believed that a referral to an audiologist was warranted, the same number of participants that would refer for cochlear implantation. Most of the respondents were not aware that a child with a confirmed permanent hearing loss should be referred to a speech pathologist or to a rehabilitation center. This was contrary to the recommendation emphasizing that early 
intervention services for infants with confirmed hearing loss have to be provided by hearing loss professionals, including audiologists, speech-language pathologists and educators of the deaf. ${ }^{8}$

\section{Knowledge of Risk Factors}

Our results showed that knowledge of factors that put a child at risk of late-onset hearing loss varied among respondents. The four main risk factors to be identified by our respondents were CMV, meningitis, mothers $>40$ years old and family history. This showed consistency with previous studies, which found that the most identified factor was meningitis, followed by family history of hearing impairment and CMV history. ${ }^{17}$ In another study, 99\% of the respondents stated that the most common factors were meningitis, family history of hearing loss, and CMV history. ${ }^{22}$ What was surprising in our study was that mothers $>40$ years old were erroneously identified as the third most important risk factor. Other risk factors, such as admission of a child for $>48$ hours to the NICU (15\%), were poorly reported in the present study, while in other studies it was one of the most identified factors. ${ }^{17,22}$ Few of the respondents (17.5\%) identified cleft palate, which was consistent with a previous study by Rogha et al. ${ }^{16}$ These data indicated that ENT physicians were not well-informed in general as to the factors that put a child at risk of late-onset hearing loss. Knowing such factors and providing continued vigilance in screening, monitoring and referrals are considered vital, particularly for physicians who are mainly responsible for the hearing management of children. ${ }^{28}$

The majority of the respondents (97.5\%) correctly identified that the right candidates for cochlear implants among hearing impaired infants had profound bilateral hearing loss. Notably, candidacy for cochlear implants has changed to include severe hearing loss, as it provides for better lingual and communication skills than hearing aids in children with severe to profound hearing loss. ${ }^{29}$

\section{Ages of Follow-up Procedures}

The knowledge of ENT physicians regarding the age for audiological testing and management was also limited. Most of the participants did not identify the right age for additional testing in newborns that did not pass the hearing screening, indicating it could be done after 1 month. Similarly, most of the participants wrongly estimated the age at which children could definitely be diagnosed as having permanent hearing loss as after 3 months. When respondents were asked to define the age when a child could begin wearing hearing aids, only 12 gave the answer as less than between 1 and 3 months. Similarly, only $35 \%$ of the respondents correctly identified less than between 1 and 6 months as the age when early intervention services were proposed for a child with permanent hearing loss. This showed that knowledge of ENT physicians was not aligned with the 1-3-6 guidelines for hearing screening. This guideline emphasizes that a child should be tested for hearing before the age of 1 month, receive additional hearing testing to confirm the degree and type of hearing loss by the age of 3 months, and receive hearing amplification and start rehabilitation by the age of 6 months, as confirmed by several studies. ${ }^{30-32}$ Most participants were not aware of the right time for each follow-up procedure. Their answers might be based on unreliable resources and the belief that hearing in infants of that age was not sufficiently developed to be tested. Not recognizing the right age for detection and intervention of hearing loss in newborns can delay adversely the process of language acquisition.

\section{Managing Hearing Loss in Children}

Most participants were not aware of the importance of hearing aids along with medication in the care of persistent conductive hearing loss in children. Hearing loss that is caused by conductive issues is often underestimated and treated as a temporary condition, and this is somewhat true, though more complicated, in the case of children. Children have a critical age for language and speech acquisition, and issues such as recurring otitis media may cause language delay and affect normal language development. ${ }^{33}$ Therefore, it is recommended that children with persistent conductive problems should have hearing aids to ensure a proper language and speech development. ${ }^{34}$

On the other hand, a majority of respondents was aware that children who received hearing aids or cochlear implants could not develop adequate speech and language skills without speech therapy or auditory rehabilitation. It is well-established that managing children with hearing loss is only successful with suitable fitted hearing aids, and through receiving suitable speech-language therapy. ${ }^{35,36}$

Unilateral and mild SNHL was another area where ENT physicians showed limited knowledge. More than half of the participants in the present study did not think, or were not sure that mild SNHL was worth the use of hearing aids in children. Moreover, almost half of the participants considered that children with unilateral hearing loss might not be fitted with a hearing aid as they had one good ear. The criteria for hearing aid fitting in adults is more restrictive than in children, with even a mild degree of hearing loss in a child being worthy of fitting hearing aids to ensure adequate language and speech acquisition, ${ }^{37-40}$ as recommended by the American Academy of Audiology guidelines for pediatric amplification. ${ }^{41}$ Unilateral hearing loss affects adversely child language development, and results in loss of localization ${ }^{42,43}$; therefore, both unilateral and mild hearing loss warrants amplification in children. ${ }^{41}$

\section{Knowledge of Hearing Tests}

Despite the fact that AABR was considered the best test for NHSP, ${ }^{44-47}$ most of the respondents believed it to be OAE. This could be because OAE is well known to most physicians as being a more reliable and quick method of hearing screening than AABR. ${ }^{48} \mathrm{~A}$ majority of the ENT physicians thought that ABR testing was better than behavioral testing, such as VRA, for estimating hearing thresholds in children. This could be because young children up to 6 months cannot actually be assessed by conventional hearing tests; therefore, objective assessments, such as ABR, are the choice for children. However, once the child is old enough to be tested through behavioral testing, such as VRA, it is preferred over ABR testing ${ }^{49}$, as recommended by the American Speech- 
Language-Hearing Association (ASHA $)^{50}$. Assuming that ABR is better than VRA could actually delay the process of managing children with hearing loss, particularly due to the lack of $A B R$ testing equipment in public hospitals in Jordan, to where the majority of children are referred. The ENT physicians are the first source of information for families regarding hearing loss and its management, and it is essential they are well-informed as to the best practice in hearing testing and hearing aids; consequently, managing children with hearing loss through proper counseling and guidance.

The present study showed that there were no statistical differences between residents and specialists in their responses to the study questions. This could be attributed to the fact that specialists are not exposed to any further training than they received as residents. However, this result was inconsistent with a previous study ${ }^{51}$, which indicated that residents had more knowledge compared with specialists. The present study also showed that there were no significant differences in answers given by participants who worked in university hospitals and other settings, possibly because similar technologies were used in all hospitals.

\section{Hearing Screening and Services in Jordan}

Despite the fact that Jordan still has no official early hearing detection and intervention programs, most of the respondents believed that they had been implemented. This could be attributed to the fact that hearing screening is easy and should be conducted at birth, and to the fact that some private centers and hospitals occasionally have the test available for patients who can afford it. Moreover, this could be attributed to the fact that a study on the efficacy of hearing screening was implemented during the time of the data collection for the present study at one of the major university hospital where a large number of the participants worked. Nearly one third of the respondents did not receive any NHS results, which was consistent with there being no official hearing screening program for newborns in Jordan, except at some private centers and at the royal medical services hospitals. The respondents were divided on their answers when they were asked if they face difficulties finding places that provide reliable audiology-related services in Jordan. This could be related to the connection of doctors with existing services and private centers. The present study showed that ENT physicians were not well-informed of hearing screening and audiological management specifically in Jordan. This could be attributed to a lack of communication between different health organizations and hospitals regarding hearing screening in Jordan.

While the results of the present study showed that a majority of respondents were aware of the significance of NHS, it also revealed a lack of knowledge in many aspects related to hearing loss in children, including specialist referral, the best methods for hearing assessment, hearing loss management in children and some risk factors of late-onset hearing loss. This was consistent with other studies, ${ }^{12,19,22}$ which indicated a poor level of knowledge among different samples of health professionals.

The limited level of knowledge could be attributed to different reasons, including unfamiliarity of the respondents with the newly implemented program and current practices related to managing children with hearing loss. ${ }^{7,52}$ Moreover, it could be related to a lack of NHS-related regulations in general, ${ }^{53}$ and in Jordan specifically. Another reason could be the lack of training and educational courses on hearing screening and audiological management. Even so, the main reason could also be attributed to the low number of children with permanent SNHL that physicians had in their practice. Only half of the respondents in the present study dealt with children with permanent SNHL in their practice during the past 3 years. In addition, the lack of follow-up information from parents of children with confirmed hearing loss was another possible reason. ${ }^{19,25}$

The present study argued for running an educational program for ENT physicians on hearing loss and its management in children. Raising awareness about the procedures of NHSPs among medical professionals in general, and specifically among ENT specialists, is critical. It is also highly advisable to run workshops and training sessions based on case studies of children with hearing loss to help ENT physicians gain practical information about hearing loss in children, and to provide them with recent updates and advances in hearing screening. ${ }^{18,25,52,53}$ The respondents themselves expressed the need for more information regarding specific aspects of audiology, such as ABR testing, acoustic reflexes and cochlear implants. Most importantly, it is essential to implement a hearing screening program that is aligned and governed by international standards.

The limitations of the present study included being based on self-reported data, where there was no way to validate the individual answers. Respondents might also have been influenced in their answers by peer opinions. However, this did not seem likely to have majorly affected the results, given the education level of the participants, and their independent comments at the end of the questionnaire, where they expressed the need for more information about specific aspects in audiology. Another limitation in the study was that many participants did not answer some of the questions, which created a considerable amount of missing data especially for the informative questions. It might be assumed that this was due to limited knowledge of the participants about specific aspects; however, this hypothesis was untested.

\section{Conclusion}

The present study showed good overall knowledge by ENT physicians about the importance of hearing screening and candidacy of infants for cochlear implantation. However, it also revealed limited knowledge in many aspects of hearing loss testing and management. This argued for the implementation of hearing screening programs, as well as educational programs on hearing loss and related aspects, such as hearing tests and hearing loss management in children.

\footnotetext{
Funding

All Agencies: Jordan University of Science and Technology Grant/Award Number: '20180325'
} 


\section{Conflict of Interests}

The authors have no conflict of interests to declare.

\section{References}

1 Watkin PM, Baldwin M, McEnery G. Neonatal at risk screening and the identification of deafness. Arch Dis Child 1991;66(10 Spec No): $1130-1135$

2 White KR, Behrens TR. The Rhode Island hearing assessment project: implications for universal newborn hearing screening. Thieme Medical Publisher; 1993

3 Olusanya BO, Ruben RJ, Parving A. Reducing the burden of communication disorders in the developing world: an opportunity for the millennium development project. JAMA 2006;296(04):441-444

4 Pimperton $\mathrm{H}$, Kennedy CR. The impact of early identification of permanent childhood hearing impairment on speech and language outcomes. Arch Dis Child 2012;97(07):648-653

5 Olusanya BO, Luxon LM, Wirz SL. Maternal views on infant hearing loss in a developing country. Int J Pediatr Otorhinolaryngol 2006;70(04):619-623

6 Olusanya BO, Newton VE. Global burden of childhood hearing impairment and disease control priorities for developing countries. Lancet 2007;369(9569):1314-1317

7 Mazlan R, Min WS. Knowledge and attitude of Malaysian healthcare professionals towards newborn hearing screening program. Malaysian Journal of Public Health Medicine 2018;20:30-39

8 American Academy of Pediatrics, Joint Committee on Infant Hearing. Year 2007 position statement: Principles and guidelines for early hearing detection and intervention programs. Pediatrics 2007;120(04):898-921

9 Peer S, Fagan JJ. Hearing loss in the developing world: evaluating the iPhone mobile device as a screening tool. S Afr Med J 2015;105 (01):35-39

10 López-Vázquez M, Berruecos P, Lopez LE, Cacho J. Attitude and knowledge of hearing loss among medical doctors selected to initiate a residency in Mexico. Int J Audiol 2009;48(03): 101-107

11 Yerraguntla K, Ravi R, Gore S. Knowledge and attitude of pediatric hearing impairment among general physicians and medical interns in coastal Karnataka, India. Indian Journal of Otology 2016;22:183-187

12 Moorjani P, Fortnum H. Dissemination of information to General Practitioners: a questionnaire survey. BMC Fam Pract 2004; 5:27-31

13 Campos AC, Shirane HY, Takemoto PV, Lourenço EA. Triagem auditiva neonatal universal: conhecimento dos pediatras e neonatologistas em Jundiaí, São Paulo, Brasil. Rev Bras Otorrinolaringol (Engl Ed) 2014;80(05):379-385

14 Danhauer JL, David KB, Johnson CE, et al. Survey of pediatricians and early hearing detection and identification programs at a precise local level: An academic medical center. In, Seminars in Hearing: (c) Thieme Medical Publishers; 2009:165-183

15 Colozza P, Anastasio ART. Screening, diagnosing and treating deafness: the knowledge and conduct of doctors serving in neonatology and/or pediatrics in a tertiary teaching hospital. Sao Paulo Med J 2009;127(02):61-65

16 Rogha M, Mokhtari E. Study of the knowledge of pediatricians and senior residents relating to the importance of hearing impairment and deafness screening among newborns. Iran J Otorhinolaryngol 2014;26(75):57-64

17 Ravi R, Gunjawate DR, Yerraguntla K, Lewis LE, Rajashekhar B. A national survey of knowledge, attitude and practices among pediatricians towards newborn hearing screening in India. Int J Pediatr Otorhinolaryngol 2017;95:9-14

18 Goedert MH, Moeller MP, White KR. Midwives' knowledge, attitudes, and practices related to newborn hearing screening. J Midwifery Womens Health 2011;56(02):147-153
19 Ross DS, Visser SN. Pediatric primary care physicians' practices regarding newborn hearing screening. J Prim Care Community Health 2012;3(04):256-263

20 Bush ML, Alexander D, Noblitt B, Lester C, Shinn JB. Pediatric hearing healthcare in Kentucky's Appalachian primary care setting. J Community Health 2015;40(04):762-768

21 Moeller MP, White KR, Shisler L. Primary care physicians' knowledge, attitudes, and practices related to newborn hearing screening. Pediatrics 2006;118(04):1357-1370

22 Ravi R, Gunjawate DR, Yerraguntla K, Rajashekhar B. Systematic review of knowledge of, attitudes towards, and practices for newborn hearing screening among healthcare professionals. Int J Pediatr Otorhinolaryngol 2018;104:138-144

23 Danhauer JL, Johnson CE, Finnegan D, et al. A case study of an emerging community-based early hearing detection and intervention program: part II. Team building with otolaryngologists and pediatricians using a survey approach. Am J Audiol 2006;15(01):33-45

24 Jafari Z, Mollasadeghi A, Baradaranfar M. Prevalence of Hearing disorders in 3-6 year old Children of Kindergartens in Yazd City. Journal of Shahid Sadoughi University of Medical Sciences 2009;16:20-25

25 Moeller MP, Eiten L, White K, Shisler L. Strategies for educating physicians about newborn hearing screening. J Acad Rehabilitative Audiol 2006;39:11-32

26 [CG60] Cg. Otitis media with effusion in under 12s: surgery. The National Institute for Health and Care Excellence (NICE). In. United States: The National Institute for Health and Care Excellence (NICE);; 2008

27 Byrne D, Noble W. Optimizing sound localization with hearing AIDS. Trends Amplif 1998;3(02):51-73

28 McCreery RW, Bentler RA, Roush PA. Characteristics of hearing aid fittings in infants and young children. Ear Hear 2013;34(06):701-710

29 Vila PM, Lieu JE. Asymmetric and unilateral hearing loss in children. Cell Tissue Res 2015;361(01):271-278

30 Lieu JEC. Permanent unilateral hearing loss (UHL) and childhood development. Curr Otorhinolaryngol Rep 2018;6(01):74-81

31 Holstrum WJ, Gaffney M, Gravel JS, Oyler RF, Ross DS. Early intervention for children with unilateral and mild bilateral degrees of hearing loss. Trends Amplif 2008;12(01):35-41

32 Erenberg A, Lemons J, Sia C, Trunkel D, Ziring P. Newborn and infant hearing loss: detection and intervention.American Academy of Pediatrics. Task Force on Newborn and Infant Hearing, 1998- 1999. Pediatrics 1999;103(02):527-530

33 Pediatrics AAo. Obstetricians ACo, Gynecologists. Guidelines for perinatal care. Amer Academy of Pediatrics; 2002

34 Erturk BB, Genc GA, Ozkan S. Comparison of Hearing Screening Protocols for Universal Newborn Hearing Screening In Turkey. J Int Adv Otol 2010;6:223-230

35 Levit Y, Himmelfarb M, Dollberg S. Sensitivity of the automated auditory brainstem response in neonatal hearing screening. Pediatrics 2015;136(03):e641-e647

36 Meena RS, Meena D, Babu D, Singh BK, Verma PC. Role of transient evoked otoacoustic emission beyond screening of hearing impairment: a study of 400 cases. Indian J Otolaryngol Head Neck Surg 2013;65(02):134-139

37 Sabo DL. The audiologic assessment of the young pediatric patient: the clinic. Trends Amplif 1999;4(02):51-60

38 ASHA. Guidelines for the Audiologic Assessment of Children From Birth to 5 Years of Age. American Speech-Language-Hearing Association (ASHA) In: USA: American Speech-Language-Hearing Association (ASHA); 2004

39 Hashemi M, Akbari ME, Razavi SS, Saadat-Niaki A, Hoseini Khameneh SM. Evaluating resident physicians' knowledge, attitude, and practice regarding the pain control in cancer patients. Iran J Cancer Prev 2015;8(01):1-10

40 Arnold CL, Davis TC, Humiston SG, et al. Infant hearing screening: stakeholder recommendations for parent-centered communication. Pediatrics 2006;117(5 Pt 2):S341-S354 
41 Wall TC, Senicz E, Evans HH, Woolley A, Hardin JM. Hearing screening practices among a national sample of primary care pediatricians. Clin Pediatr (Phila) 2006;45(06):559-566

42 Vila PM, Lieu JE. Asymmetric and unilateral hearing loss in children. Cell Tissue Res 2015;361(01):271-278

43 Lieu JEC. Permanent unilateral hearing loss (UHL) and childhood development. Curr Otorhinolaryngol Rep 2018;6(01):74-81

44 Halliday LF, Tuomainen O, Rosen S. Language development and impairment in children with mild to moderate sensorineural hearing loss. J Speech Lang Hear Res 2017;60(06):1551-1567

45 Friedmann N, Szterman R. Syntactic movement in orally trained children with hearing impairment. J Deaf Stud Deaf Educ 2006;11 (01):56-75

46 Koehlinger KM, Van Horne AJO, Moeller MP. Grammatical outcomes of 3- and 6-year-old children who are hard of hearing.J Speech Lang Hear Res 2013;56(05):1701-1714

47 Ching T, Galaster J, Grimes A, et al. American Academy of Audiology clinical practice guidelines: Pediatric amplification. Reston, VA: American Academy of Audiology; 2013
48 Moeller MP, Tomblin JB, Yoshinaga-Itano C, Connor CM, Jerger S. Current state of knowledge: language and literacy of children with hearing impairment. Ear Hear 2007;28(06):740-753

49 Sabo DL. The audiologic assessment of the young pediatric patient: the clinic. Trends Amplif 1999;4(02):51-60

50 ASHA. Guidelines for the Audiologic Assessment of Children From Birth to 5 Years of Age. American Speech-Language-Hearing Association (ASHA) In: USA: American Speech-Language-Hearing Association (ASHA); 2004

51 Hashemi M, Akbari ME, Razavi SS, Saadat-Niaki A, Hoseini Khameneh SM. Evaluating resident physicians' knowledge, attitude, and practice regarding the pain control in cancer patients. Iran J Cancer Prev 2015;8(01):1-10

52 Yoshinaga-Itano C, Sedey AL, Coulter DK, Mehl AL. Language of early- and later-identified children with hearing loss. Pediatrics 1998;102(05):1161-1171

53 Perth: Health Networks Branch DoH, Western Australia. Clinical Guidelines for Paediatric Cochlear Implantation Neurosciences and the Senses Health Network In; 2011 